\title{
British Thoracic Society Winter Meeting 2005
}

\section{T M A Wilkinson, R Baghai-Ravery, W R Perera}

An overview of some of the key topics presented at the BTS Winter Meeting held in London in December 2005

T he annual winter British Thoracic Society (BTS) meeting held in London on 7-9 December 2005 combined a fascinating retrospective of past achievements in respiratory medicine while looking forward to the challenges that lie ahead. The meeting provided, as usual, a vital platform for clinicians to share best practice and to keep abreast of the rapidly advancing speciality. A highlight was the celebration of the 20th anniversary of British Lung Foundation, with a review of the major advances in respiratory medical research made in recent years.

\section{CHRONIC OBSTRUCTIVE PULMONARY DISEASE}

The priority given to chronic obstructive pulmonary disease (COPD) at this meeting reflected both the clinical burden of disease and the current interest in terms of clinical and basic research in this field. In a lively "pro-con" debate, some of the more controversial issues in disease management were addressed. Arguments included the new BTS President Professor Peter Calverley's persuasive case that COPD was indeed a useful diagnostic term, as well as lively debate on the evidence for the use of inhaled corticosteroids. With the radical reforms to the provision of home oxygen imminent, a number of sessions concentrated on the new service and the potential impact on patients and providers alike. A presentation highlighted the increase in service provision required to support home oxygen assessments, ${ }^{1}$ while posters highlighted the benefits of developing a register of COPD patients suitable for long term oxygen therapy (LTOT) ${ }^{2}$ and the efficacy of ambulatory oxygen in pulmonary rehabilitation. ${ }^{3}$

The pathogenesis of airways obstruction and exacerbations were the focus for presentations on the role of infection and inflammation in COPD. Highlighting the recent advances in our understanding of this condition, presentations ranged from the findings of a study of antibiotic therapy which reduced airway inflammation, ${ }^{4}$ evidence for the role of respiratory syncytial virus (RSV) in airway inflammation and disease progression in stable COPD, ${ }^{5}$ to description of in vitro models of the airway for studying innate immune responses. ${ }^{6}$ Current thinking on the provision of services for COPD patients was addressed on the final day, underlining the role multidisciplinary community based teams may play in reducing hospital admissions and improving outcomes. ${ }^{7}$

\section{PULMONARY REHABILITATION}

The posters on pulmonary rehabilitation provided useful insights into developments in the application of this treatment. Reassuringly, two studies $^{89}$ indicated that obese patients with COPD do benefit from pulmonary rehabilitation, while admission to hospital for exacerbations can be reduced in severe disease by physiotherapy led community disease management. ${ }^{10}$

Findings were presented suggesting that occupational therapy focusing on activity management improves both health status ${ }^{11}$ and patient satisfaction. ${ }^{12}$ While anxiety and depression were identified as risk factors for failure to complete rehabilitation, ${ }^{13}{ }^{14}$ targeted interventions such as anxiety management may improve outcomes in this area. ${ }^{15}$

\section{ASTHMA}

One of the meeting's first sessions highlighted the continued advances made by UK researchers in the understanding of airway inflammation in asthma. Work on the inflammatory profile of a phenotype of steroid resistant non-eosinophilic asthma was presented, ${ }^{16}$ and the deleterious pro-inflammatory effects of inhaled pollutants were described using a novel 2 hour "real life" exposure on London's Oxford Street.

The epidemiology of asthma continues to be an active area of research; a spoken session cast light on the pathogenesis of thunderstorm outbreaks of asthma, ${ }^{17}$ and the use of cluster analysis models to identify and predict prognosis in distinct asthma phenotypes. ${ }^{18}$ An optimistic tone was set by the session on "Looking towards new treatments for asthma" with presentations on the possible future role of targeted anti-cytokine and anti-IgE therapy.

\section{BASIC SCIENCE}

Collaboration between the British Association for Lung Research (BALR) and the BTS produced a day long symposium focusing on the current state of the art in stem cell research and the possible future therapeutic indications and benefits in respiratory disease. Another symposium in the area of basic science covered work on the genetics of airways disease, and there were several presentations concentrating on mechanisms common to a number of lung diseases. This included work on the mechanisms of differentiation of fibroblasts to myofibroblasts, ${ }^{19}$ the role of glutathione S-transferase Pl (GSTPl) polymorphisms in controlling lung development and repair, ${ }^{20}$ and the encouraging work on the role that retinoid therapy may play in alveolar repair. ${ }^{21}$

\section{OCCUPATIONAL LUNG DISEASE}

The symposium on occupational lung disease informed on how the Health and Safety Executive targets on reducing work related ill health will be met, suggested a model for providing excellence in service, and discussed limitations and practical approaches to the diagnosis of occupational lung diseases. The problem of under-diagnosis and under-reporting of occupational asthma was highlighted following a pilot surveillance scheme in Scotland, ${ }^{22}$ with concerns about variability in diagnostic standards revealing the need for better training. ${ }^{23}$

RESPIRATORY MUSCLES AND NIV Important developments in physiological assessment of respiratory diseases, with focus on the use of magnetic nerve stimulation and oesophageal electromyography were presented. The Moran Campbell Lecture was introduced by Professor John Gibson who gave an insight into the enthusiasm of the late Dr Campbell and reviewed his seminal work on the mechanics of breathing, sensation of dyspnoea, and the safe administration of oxygen therapy. This was followed by Dr Michael Polkey's lecture on neuromuscular limitations in health and disease in which he explained the clinical relevance of cortical drive and muscle fatigue, and alluded to earlier spoken sessions on quadriceps muscle contractility $^{24}$ and endurance..$^{25}$

\section{SLEEP DISORDERED BREATHING AND OBSTRUCTIVE SLEEP APNOEA}

The increasingly recognised clinical problem of obstructive sleep apnoea (OSA) 
was highlighted in a number of sessions. One study showed that the need for continuous positive airway pressure (CPAP) therapy cannot be predicted reliably by a clinical questionnaire for patients referred from primary care. ${ }^{26}$ Other work described the effects of CPAP on attenuation of the cardiovascular response to arousal ${ }^{27}$ and improving vasomotor tone, ${ }^{28}$ and hence a role for this treatment in reducing cardiovascular risk in this patient group. Another study attributed the increase in cardiovascular mortality seen in OSA to findings of impaired cardiac metabolism and dysfunction. ${ }^{29}$

\section{ADULT RESPIRATORY DISTRESS SYNDROME (ARDS)}

Presentations demonstrating advances in the understanding of the basic pathological mechanisms of ARDS from both in vitro and murine models explained the mechanism of stretch induced lung injury through the ERKl/ 2 pathway, ${ }^{30} 31$ and the importance of TNF receptor 1 signalling in stretch induced pulmonary inflammation. ${ }^{32} \mathrm{~A}$ potential role for vascular endothelial growth factor (VEGF) in the regenerative phase of ARDS was suggested by a presentation of its activity on primary lung epithelial cells. ${ }^{33}$

\section{PULMONARY EMBOLISM AND PULMONARY HYPERTENSION}

Presentation of audits on the diagnosis of pulmonary embolism (PE) suggested that the BTS guidelines may be poorly implemented in the absence of local agreements within hospitals. ${ }^{34-37}$ Early discharge following anticoagulation was shown to be safe for selected patients diagnosed with $\mathrm{PE}^{38}$ and a prospective 1 year randomised study of 3 or 6 months' anticoagulation for uncomplicated PE showed no difference in recurrence, deaths, or major haemorrhage. ${ }^{39}$ However, another study suggested that secondary pulmonary hypertension is a common problem even after 6 months' anticoagulation and deserves further consideration. ${ }^{40}$

A comprehensive symposium on pulmonary arterial hypertension covered the spectrum of pathogenic causes for this condition, stressed the importance of molecular genetics, suggested novel therapies targeting multiple pathogenic pathways, and finally discussed the role of biomarkers and monitoring of outcomes.

\section{MALIGNANT DISEASE}

Lung cancer and mesothelioma were discussed in two well attended symposia. The first session was a multidisciplinary presentation addressing issues such as optimum services for investigation of patients with suspected lung cancer, information given to patients during the diagnostic pathway, the crucial role of the lung cancer specialist nurse, and the role of palliative chemotherapy in patients with poor performance status. The second symposium reminded us of the rising incidence of mesothelioma and highlighted the key differences in the relationships between asbestos exposure and lung cancer and asbestos exposure and mesothelioma.

The yield of bronchoscopy for detecting lung cancer in smokers and exsmokers aged over 50 presenting solely with pneumonia was presented, ${ }^{41}$ and the usefulness of targeted bronchial cytology in lung cancer patients with normal bronchoscopic findings was presented by another group. ${ }^{42}$ The benefits of implementing a "safety net" protocol and a coded radiographic reporting system for all chest radiographs were also presented..$^{43}$ Several reports on changes in the organisation of lung cancer services described increases in the total number of CT scans, in the number of CT scans performed before bronchoscopy, and in the number of CT guided biopsies, with a parallel decline in the number of fibreoptic bronchoscopies. $^{45-48}$ The surgical experience of patients deemed unfit for surgery according to the BTS guidelines, ${ }^{49}$ as well as in patients with stage III nonsmall cell lung cancer undergoing surgical resection after neoadjuvant chemotherapy, was reviewed. ${ }^{50}$

\section{PLEURAL DISEASE}

A session on pleural infection included a randomised trial comparing intrapleural urokinase with video assisted thoracoscopic surgery for the treatment of empyema in children, ${ }^{51}$ and data from the MRC/BTS MISTl trial cohort on the survival significance of different bacterial classes in pleural infection. ${ }^{52}$ The finding that management of spontaneous pneumothorax in well selected patients could be safely achieved with the use of a thoracic vent device may alter practice. ${ }^{53}$ The clinical usefulness of ultrasound in the detection of malignant pleural disease with a pleural effusion was presented, ${ }^{54}$ and the role of "blind" trucut pleural biopsy in the investigation of pleural effusion was also described. ${ }^{55}$

\section{CYSTIC FIBROSIS (CF)}

A debate on the best way to diagnose CF related diabetes followed data on the long term effects of diabetes and insulin treatment on clinical status and lung function..$^{56}$ The effects of air pollutants and seasonality on CF exacerbations ${ }^{57}$ and a national survey on the management of $\mathrm{CF}$ exacerbations by paediatric and adult CF physicians were also presented..$^{58}$ The issue of systemic and airway inflammation in stable state and at exacerbations of CF was addressed in several posters, ${ }^{59-62}$ and the difficult issue of palliative care in CF was addressed in an interesting session. ${ }^{63}$

\section{PULMONARY INFECTION}

Pulmonary infection held a prominent place again at the BTS winter meeting with symposia on tuberculosis (TB) and respiratory viruses as well as several spoken and poster discussion sessions.

Professor Stewart Cole delivered a fascinating Snell memorial lecture on the genomics of Mycobacterium tuberculosis. Spoken sessions on TB varied from a phase II trial looking at the safety of MVA85A vaccination in latent $\mathrm{TB}^{64}$ to trends in the diagnosis of extrapulmonary $\mathrm{TB}^{65}$ and an evaluation of the association of new diagnosis with immigration profiles. ${ }^{66}$ The BTS Young Investigators Prize was awarded for research showing the importance of Oncostatin $\mathrm{M}$ in inducing matrix metalloproteinases (MMP) which drives matrix degradation and cavitation in TB. ${ }^{67}$ A national survey on contact tracing was presented ${ }^{68}$ and experience of contact tracing of farm workers who had been in contact with bovine TB discussed. ${ }^{69}$ New diagnostic and treatment monitoring techniques were highlighted, including the use of the Elispot test in the detection of active ${ }^{70}$ and latent ${ }^{71} \mathrm{~TB}$ and messenger RNA as a marker of treatment response in pulmonary $\mathrm{TB}^{72}$

\section{AND FINALLY....}

The British Lung Foundation's birthday was celebrated with an impressive review of important research findings over the last 50 years including the epidemiological studies that linked smoking with lung cancer, the development of the fibreoptic bronchoscope and more effective antituberculous therapy, and finally a look into the future potential for lung tissue regeneration. Congratulations are due to Drs Patel and O'Kane for their success in the Young Investigators prizes. Professor Malcom Green was awarded the BTS Honorary Medal for his notable contributions to respiratory physiological research and the establishment of the British Lung Foundation in 1985.

The new BTS President, Professor Peter Calverley, addressed the meeting and reflected on the achievements of the past. He went on to quote the poet Robert Frost:

$$
\text { "... and miles to go before I sleep" }
$$

and outlined his aspirations for the future direction of both clinical practice and research in respiratory medicine and the many challenges that lie ahead. 
Thorax 2006;61:280-283.

doi: $10.1136 /$ thx.2006.061135

\section{Authors' affiliations}

T M A Wilkinson, R Baghai-Ravery,

W R Perera, Academic Unit of Respiratory Medicine, Royal Free and University College Medical School, London, UK

Correspondence to: $\operatorname{Dr}$ T M A Wilkinson, Academic Unit of Respiratory Medicine, Royal Free and University College Medical School, London NW3 2PF, UK; tomw1970@hotmail. com

Funding: none

Competing interests: none declared

\section{REFERENCES}

1 Quint JK, Ward L, Monaghan M, et al. The new home oxygen service: assessing the impact on respiratory units. Thorax 2005;60(Suppl II):S17.

2 Ambalavanan S, Moloney D, Miles JF, et al. Value of an oxygen register in identifying patients eligible to receive long term oxygen therapy in chronic obstructive pulmonary disease. Thorax 2005;60(Suppl II):P34

3 Gray F, Smith A, Coombs C, et al. The effect of ambulatory oxygen in patients during pulmonary rehabilitation. Thorax 2005;60(Suppl II):P35.

4 Siva R, Monteiro W, Parker D, et al. The effect of levofloxacin on neutrophilic airway inflammation in stable state chronic obstructive pulmonary disease: a randomised, double blind, placebo controlled trial. Thorax 2005;60(Suppl II):P101.

5 Wilkinson TMA, Perera W, Hurst JR, et al Relationship between RSV detection and airway inflammation in patients with COPD. Thorax 2005;60(Suppl II):P107.

6 Foo S, Wark P, Bucchieri F, et al. In vitro models of rhinovirus infection of primary bronchial epithelial cells from smokers. Thorax 2005;60(Suppl II):P105

7 Hewson M, Plant PK, Walker V. Impact of primary care trust based chronic obstructive pulmonary disease teams at reducing hospital admissions in Leeds in 2003 and 2004. Thorax 2005:60(Suppl II):P139.

8 Evans RA, Hall ME, Steiner MC, et al. Does body mass index influence the outcome of pulmonary rehabilitation in patients with chronic obstructive pulmonary disease? Thorax 2005;60(Suppl II):P40.

9 Ross DJ, Darbyshire K, Johnson R, et al. Is outcome in pulmonary rehabilitation related to body mass index? Thorax 2005;60(Suppl II):P41.

10 Pushparajah S, McClellan R, Henry A, et al. Does a physiotherapist led community based disease management programme in chronic obstructive pulmonary disease patients affect hospital admissions with acute exacerbations? Thorax 2005;60(Suppl II):P43

11 Elliott C, Bone M. Evaluation of an activity management (better breathing) clinic run by occupational therapy for patients with chronic obstructive pulmonary disease. Thorax 2005;60(Suppl II):P42

12 Elliott C, Bone M. Occupational therapy intervention in chronic obstructive pulmonary disease. Thorax 2005;60(Suppl II):P44

13 Garrod R, Marshall J, Barley E, et al. Factors associated with success and failure of pulmonary rehabilitation. Thorax 2005;60(Suppl II):P46.

14 Carpenter R, Cadwallader T, Doherty MJ. Dropouts from a pulmonary rehabilitation programme. Thorax 2005;60(Suppl II):P50.

15 Woods C, Fennerty A. An anxiety management programme for patients with severe obstructive airways disease. Thorax 2005;60(Suppl II):P48.

16 Berry MA, Morgan A, Green RH, et al. Clinical and pathological features of non-eosinophilic asthma: a distinct asthma phenotype associated with inhaled corticosteroid resistance. Thorax 2005;60(Suppl II):S2
17 Pulimood TB, Cordon J, Nasser SM. Sensitivity to Alternaria alternata in grass pollen sensitive asthmatics is an important factor in thunderstorm outbreaks of asthma. Thorax 2005; 60/Suppl II): 590

18 Haldar P, Green RH, Berry MA, et al. Heterogeneity in refractory asthma: the use of cluster analysis to identify distinct cohorts. Thorax 2005;60(Suppl II):S94.

19 Krupiczojc MA, Scotton CJ, Laurent GJ, et al. Activation of PAR I by FXA induces fibroblast to myofibroblast differentiation. Thorax 2005;60(Suppl II):S60.

20 Holley S, Fryer A, Carroll W, et al. Functional analysis of GSTP1 haplotypes on cell growth and apoptosis in NIH3+3 fibroblasts. Thorax 2005;60(Suppl II):S59.

21 Maden M, Gilthorpe A, Annan A, et al. Retinoid induction of alveolar regeneration in a mouse model of emphysema. Thorax 2005;60(Suppl II):S132.

22 Ayres JG, Semple S, Scaife AR, et al. Piloting a surveillance scheme for occupational airways disease in Scotland: Scottishshield. Thorax 2005;60(Suppl II):P72.

23 Naylor S, Elms J, Curran AD, et al. Variation in diagnostic methods for occupational asthma. A national study. Thorax 2005;60(Suppl II):P66.

24 Reyes D, Swallow EB, Cetti E, et al. Quadriceps strength predicts mortality in patients with chronic obstructive pulmonary disease. Thorax 2005;60(Suppl II):S147.

25 Swallow EB, Gosker HR, Ward KA, et al. Quadriceps muscle endurance in patients with chronic obstructive pulmonary disease; correlation with muscle biopsy data. Thorax 2005;60(Suppl II):S1 46

26 Menzies SM, Stradling JR. Screening questionnaires in patients referred to a sleep clinic cannot predict which individuals do not require continuous positive pressure treatment for obstructive sleep apnoea. Thorax 2005;60(Supp II):S1 13.

27 O'Driscoll DM, Simonds AK, Morrell MJ. Acute cardiovascular response to arousal in obstructive sleep apnoea before and after continuous positive pressure treatment. Thorax 2005;60(Suppl II):S115.

28 Cross MD, Al-Abri M, Newby DE, et al. Randomised controlled trial evidence that continuous positive airway pressure improves vascular function in obstructive sleep apnoea hypopnoea syndrome. Thorax 2005;60(Suppl II): $S 117$.

29 West SD, Schevermann-Freestone M, Watson GC, et al. Patients with obstructive sleep apnoea have impaired cardiac metabolism and diastolic dysfunction compared to controls. Thorax 2005;60(Suppl II):S116.

30 Pinhu L, Griffiths MJD. The extracellular signal related kinase pathway mediates mechanotransduction in A549 cells. Thorax 2005;60(Suppl II):S36.

31 Pinhu L, Wilson MR, Takata M, et al. Chemokine production by mouse lungs subjected to injurious mechanical ventilation requires extracellular regulated kinase 1/2 pathway activity. Thorax 2005;60(Suppl II):S35.

32 Wilson MR, Choudhury S, Takata M. Stretch induced pulmonary oedema is mediated by tumour necrosis factor receptor I is signalling in mice. Thorax 2005;60(Suppl II):S37.

33 Roberts JR, Perkins GD, Thickett DR. Vascular endothelial growth factor: not just endothelial cell growth factor? Thorax 2005;60(Suppl II):S38.

34 Scriven N, Rose P, Arya R, et al. Diagnosis and treatment of pulmonary embolism: findings from the VERITY VTE treatment registry. Thorax 2005;60(Suppl II):S152.

35 Sarkar PK, Kaneri S, Farrugia M et al. Can the use of BTS pulmonary embolism guidelines help in reducing unnecessary $\mathrm{CT}$ pulmonary angiogram scanning? Thorax 2005;60(Suppl II):S153.

36 Goodman AL, Robinson GV, Davies CWH, et al. Computed tomography pulmonary angiogram requests for the investigation of acute pulmonary emboli. How appropriate are they? Thorax 2005;60(Suppl II):P1 23.

37 Power L, Withers NJ. Lack of clinical probability assessment in patients investigated for pulmonary embolism. Thorax 2005;60(Suppl II):P124.
38 Davies CWH, Wimperis J, Green ES, et al. Outpatient treatment of patients with pulmonary embolism. Thorax 2005;60(Suppl II):S155.

39 Campbell IA, on behalf of the Research Committee. BTS study of three versus six months' anticoagulation for pulmonary venous thromboembolism. Thorax 2005;60(Suppl II):S151.

40 Simmonds N, Sheth A, Madden BP. Pulmonary embolism and pulmonary hypertension: is our follow up adequate? Thorax 2005; 60(Suppl II):S156.

41 Houston K, Singh H, Taggart SCO, et al. Prospective study of the value of bronchoscopy to screen for lung cancer in smokers and ex-smokers aged over 50 years with pneumonia. Thorax 2005:60(Suppl II):S12.

42 Bari S, Stock DA, Smyth CM, et al. The value of targeted bronchial cytology in lung cancer patients with a normal bronchoscopy. Thorax 2005;60(Suppl II):S13

43 Singh H, Taggart SCO, Turkington PM, et al. One year's experience of a chest radiograph "safety net" protocol. Thorax 2005;60(Suppl II):S23.

44 Stock DA, Huhes J, McCann C, et al. Five year experience of an X-ray coding system in lung cancer diagnosis. Thorax 2005;60(Suppl II):S25

45 Slade M, Pengelly G, MacMullen H. Impact of a coordinated quality improvement programme upon yield of bronchoscopy in suspected lung cancer. Thorax 2005;60(Suppl II):S14.

46 Strawson EE, Patterson A, Stakes TC, et al. Change in practice in the diagnosis of lung cancer in Greenwich 1998-2004. Thorax 2005:60(Suppl II):S79.

47 Heinink RA, Ashenford S, Singh J, et al. Should bronchoscopy be the initial investigation in patients presenting with haemoptysis and an abnormal chest $x$ ray? Thorax 2005;60/Suppl II):P186.

48 Heinink RA, Fiddler A, Stretton E, et al. Should computerised tomography precede fibreoptic bronchoscopy in a district general hospital setting? Thorax 2005;60(Suppl II):P187.

49 Krishna Moorthy PS, Khan R, Khalil JF, et al. The strength of British Thoracic Society guidelines in determining the outcome for lung cancer surgery: Birmingham Heartlands Hospital's experience. Thorax 2005;60(Suppl II):S136.

50 Krishna Moorthy PS, Khan R, Marzouk JF, et al. Half decade of Birmingham's experience in looking at surgical resections on patients with stage III non-small cell lung cancer following neoadjuvant therapy. Thorax 2005;60(Supp II):P166.

51 Sonnappa S, Cohen G, Van Doorn C, et al. Randomised trial comparing chest drain with intrapleural urokinase verus video assisted thoracoscopic surgery for the treatment of empyema in children. Thorax 2005;60/Suppl II):S84.

52 Maskell NA, Batt S, Hedley EL, et al. The survival significance of different bacterial classes in pleural infection: data from the MRC/BTS MISTI trial cohort. Thorax 2005;60(Suppl II):S86.

53 Ambalavanan S, Miles JF. Outpatient management of pneumothorax. Thorax 2005;60(Suppl II):S89

54 Qureshi NR, Gleeson FV. The clinical utility of ultrasound in detecting malignant pleural disease in the presence of a pleural effusion. Thorax 2005;60(Suppl II):S88

55 Singh H, Blaikley J, Ormerod LP. The role of "blind" trucut pleural biopsy in the investigation of an exudative pleural effusion. Thorax 2005;60(Suppl II):P174.

56 Mohan K, Israeel K, Miller H, et al. Long term effects of diabetes and insulin treatment on clinical status and lung function in cystic fibrosis. Thorax 2005:60(Suppl II):S75

57 Jarad NA, Powell T, De Jaeger J, et al. Air pollutants, seasonal variation and pulmonary exacerbations in a cohort of adult cystic fibrosis patients. Thorax 2005;60(Suppl II):P137.

58 Higgs S, Jarad NA. National United Kingdom survey of cystic fibrosis pulmonary exacerbation: management variation amongst paediatric and adult physicians. Thorax 2005:60(Suppl II):P136.

59 Gray RD, Imrie M, Boyd AC, et al. Longitudinal proteomic analysis of spontaneous sputum to 
assess lung inflammation in cystic fibrosis. Thorax 2005;60(Suppl II):P85

60 Sarfaraz S, Wong FS, Jarad NA

Proinflammatory cytokines in adult cystic

fibrosis patients in a stable state and during

pulmonary exacerbations. Thorax 2005;60/Suppl II):P131.

61 Rao S, Wright AKA, Range S, et al. CD14+CD16+ blood monocytes in cystic fibrosis. Thorax 2005;60(Suppl II):P133.

62 McKeon DJ, Cadwallader KA, Condliffe AM, et al. The function and fate of neutrophils in cystic fibrosis. Thorax 2005;60(Suppl II):P135.

63 Bourke SJ, Gascoigne AD, Heslop K, et al. Palliative care needs of patients with advanced cystic fibrosis. Thorax 2005;60(Suppl II):S78.

64 Sander CR, Pathan A, Gleeson F, et al.

Phase II clinical trial of MVA85A in individuals with latent tuberculosis: the first subunit TB vaccine in clinical trial. Thorax 2005;60(Suppl II):S46.

65 Abubakar I, Crofts J, Sonnenberg P, et al. Trends in incidence and microbiological confirmaton of extrapulmonary tuberculosis in England and Wales 1999-2003. Thorax 2005;60(Suppl II):S49.

66 Duraira S, Davies PDO. Increasing tuberculosis in England and Wales compared with a decreasing trend in the USA: a matter of migration. Thorax 2005;60(Suppl II):S51

67 O'Kane CM, Elkington PTG, Friedland JS Oncastatin $M$ : a novel cytokine in tuberculosis that drives tissue destruction. Thorax 2005;60(Suppl II):T2.

68 Anderson SR, Watson JM, Campbell I. Contact tracing in pulmonary tuberculosis: a survey of current practice, 2004. Thorax 2005;60(Suppl II):P161.

69 Dodds SEA, Sheldon CD. Is contact tracing of any value for farmers and farm workers who have been in contact with bovine tuberculosis? Thorax 2005;60/Supp II):P160.

70 Boyd AE, Ashcroft A, Bothamley GH The diagnosis of active tuberculosis and the Elispot test. Thorax 2005;60(Suppl II):S50

71 Boyd AE, Ashcroft A, Bothamley GH. Elispot test in diagnosis of latent tuberculosis. Thorax 2005;60(Suppl II):P156.

72 Perrin FMR, Parsons YN, Breen RAM, et al. Messenger RNA as marker of treatment response in pulmonary tuberculosis. Thorax 2005;60(Suppl II):S128.

\section{LUNG ALERT}

COPD in never smokers: a significant problem?

$\Delta$ Celli BR, Halbert RJ, Nordyke RJ, et al. Airway obstruction in never smokers: results from the Third National Health and Nutrition Examination Survey. Am J Med 2005;1 18:1364-72

C hronic obstructive pulmonary disease (COPD) is rarely considered in people who have never smoked. This paper reviews the results of a large US survey which involved a detailed questionnaire, physical examination, and spirometric testing. It looks particularly at airways obstruction in lifelong non-smokers.

A total of 10276 people aged 30-80 years had spirometric evidence of airway obstruction in this cohort. The overall prevalence of obstructive airways disease was 165 per 1000 . Never smokers made up $42 \%$ of the sampled group. The prevalence of airway obstruction in this group was 91 per 1000, 68.5\% of whom reported no history of either asthma or COPD. The impact of other known risk factors for COPD such as occupational dust exposure, air pollution, and environmental tobacco smoke were assessed by multivariate analysis. None of these was associated with a significantly increased risk. A significantly increased risk was noted with increasing age, male sex, low body mass index, and a history of allergy.

These data can be extrapolated to suggest that there are 4.6 million lifelong non-smokers in the US with obstructive airways disease. Airways reversibility was not assessed, so an unquantified proportion of these patients could have asthma. Other known risk factors for COPD were not found to contribute in this study, although self-reporting of exposure may be inaccurate.

Further research into COPD in never smokers is warranted to clarify the aetiology, prognosis, and clinical significance of this poorly understood group of patients.

S Grundy
Specialist Registrar, Royal Oldham Hospital, UK; Seamusagrundy@aol.com

\section{LUNG ALERT}

Inhaled hypertonic saline, mechanisms, and improved lung function in cystic fibrosis $\Delta$ Donaldson SH, Bennett WD, Zeman KL, et al. Mucus clearance and lung function in cystic fibrosis with hypertonic saline. N Engl J Med 2006;354:241-50

his study compared the effect of inhaled hypertonic saline on 24 patients with cystic fibrosis over a 28 day period. Subjects were assigned to two groups receiving pretreatment with either amiloride or placebo before saline inhalation. One hour mucus clearance rates, lung function tests, and quality of life scores were used as outcome measures.

One hour mucus clearance rates were significantly increased compared with baseline levels in both groups. However, only the placebo pretreatment group showed a measurable increase over a sustained period of $>8$ hours ( 1 hour mucus clearance rate $14.0(2.0) \%$ in the placebo pretreatment group compared with $7.0(1.5) \%$ in the amiloride pretreatment group, $\mathrm{p}=0.02$ ). Lung function tests showed an improvement in forced vital capacity (FVC) between baseline and treatment in the placebo group $(p=0.05)$ but not in the amiloride pretreatment group $(\mathrm{p}=0.83)$. Similar results were found for forced expiratory volume in 1 second $\left(\mathrm{FEV}_{1}\right)$, forced expiratory flow at $25-75 \%$ of $\mathrm{FVC}\left(\mathrm{FEF}_{25-75}\right)$, and quality of life scores. In vitro experiments showed sustained hydration of airway surface liquid with hypertonic saline, a response inhibited by amiloride.

This study shows that inhalation of hypertonic saline produces a modest but sustainable increase in mucus clearance rates, lung function tests, and quality of life in patients with cystic fibrosis. This beneficial effect was negated by pretreatment with amiloride. Hydration of airway surface liquid may be an important underlying mechanism. 